\title{
Evaluation of ethanol gas sensing properties of ZnO nanopowder doped with $\mathrm{Cu}$ and $\mathrm{Fe}$
}

\author{
A. Ahmadi Daryakenari ${ }^{1}$, M. R. Vaezi $^{1 \star}$, T. Ebadzadeh ${ }^{1}$ and M. Ahmadi Daryakenari ${ }^{2}$ \\ ${ }^{1}$ Division of Nanotechnology and Advanced Materials, Materials and Energy Research Center, Karaj, Iran. \\ ${ }^{2}$ Amirkabir University, Tehran, Iran.
}

Accepted 24 Febraury, 2012

\begin{abstract}
Zinc oxide $(\mathrm{ZnO})$ is one of the most important metal oxides having various applications in gas sensors. In the present work, ZnO nanoparticles were synthesized via sol-gel method. The nanopowder was then hydraulic-pressed and pre-sintered at $400^{\circ} \mathrm{C}$ to be molded into tablets with radius of $13 \mathrm{~mm}$ and thickness of $1.4 \mathrm{~mm}$. Then, the sensor characteristics of $\mathrm{ZnO}$ nanopowder tablets were evaluated with respect to the ethanol. Finally, the tablets were doped with iron $(\mathrm{Fe})$ and copper $(\mathrm{Cu})$, and the effect of doping on sensing properties was studied.
\end{abstract}

Key words: Zinc oxide, sensitivity, ethanol, sol-gel, dopants.

\section{INTRODUCTION}

Oxide semiconductor nanostructures have been widely investigated in recent years because of their excellent properties (Bahari et al., 2008) and application in novel optical, electrical and mechanical devices, such as photovoltaic solar cells, luminescence, biomedicine, photocatalysis, light-emitting diodes (LEDs), varistors and optoelectronic nanodevices (Jiaqiang et al., 2008; Guangjian et al., 2003; Min-Hung et al., 2006; Boukos et al., 2007; Carotta et al., 2009).

Zinc oxide $(\mathrm{ZnO})$ is an n-type II to $\mathrm{VI}$ semiconductor with wide band gap of $3.37 \mathrm{eV}$, large exciton binding energy ( 60 meV), strong emission, large saturation velocity $(\sim 3.2 \times 107 \mathrm{~cm} / \mathrm{s})$ and high breakdown voltage (Zi-qiang et al., 2006; Yintang, 2008). These properties make it a promising material for optoelectronic devices in the ultra violet (UV) and blue region of the electromagnetic spectrum (Lima et al., 2007), optical or display devices, solar cells (Lima et al., 2007; Caglar et al., 2007) catalysis (Yadav et al., 2009) cantilevers production, piezoelectric applications (Carotta et al., 2009), superficial acoustic waves (SAW) (Gomez and Olvera, 2006) and humidity (Yadav et al., 2009) and gas sensors

${ }^{*}$ Corresponding author. E-mail: vaezi9016@yahoo.com or m_r_vaezi@merc.ac.ir. Tel: +98- 261-6204131. Fax: +98- 2616201888.
(Sonawane et al., 2008). Furthermore, $\mathrm{ZnO}$ is one of the most outstanding metal oxide semiconductor that is vastly used in ethanol gas sensing. Because of its stoichiometric deviation due to non-intrinsic defects, zinc oxide with wurtzite structure (HCP) is an n-type semiconductor, having very useful electrical and optical properties (Mosely, 1997; Zeng et al., 2003). Meanwhile, one way to improve gas sensing property is by doping with other element and or oxides (Niu and Du, 2004). The most important element that is used as dopants in $\mathrm{ZnO}$ are Al, In, $\mathrm{Cu}, \mathrm{Fe}, \mathrm{Sn}$, etc., (Paraguay et al., 2000). For the present work, $\mathrm{Cu}$ and Fe are chosen as dopants in $\mathrm{ZnO}$.

\section{EXPERIMENTALS}

In the experiments, methanol was used as organic solvent, mono ethanol ammine (MEA) as surfactant and zinc acetate $\left(\mathrm{Zn}\left(\mathrm{CH}_{3} \mathrm{COO}\right)_{2} \cdot 2 \mathrm{H}_{2} \mathrm{O}\right)$ as starting material. All the sols were prepared in a volume of $50 \mathrm{cc}$ and concentration of $0.5 \mathrm{M}$. Weight ratio of MEA to zinc acetate in the sols was set to be 1 . First, zinc acetate dihydrate was dissolved in a mixture of methanol and MEA at room temperature. After the vigorous stirring by a magnetic bar for $1 \mathrm{~h}$, the solution became homogeneous and clear, and allowed to age for $24 \mathrm{~h}$. Then, the aged solution was heated at $200^{\circ} \mathrm{C}$ for 3 $\mathrm{h}$. The remaining black sediment at the bottom of the container is called the green nanoparticle (GNP). Next, the GNP was calcined at $500^{\circ} \mathrm{C}$ which was determined by the thermo-gravimetric analysis and differential thermal analysis, (TGA - DTA, STA 1640, Plymer 


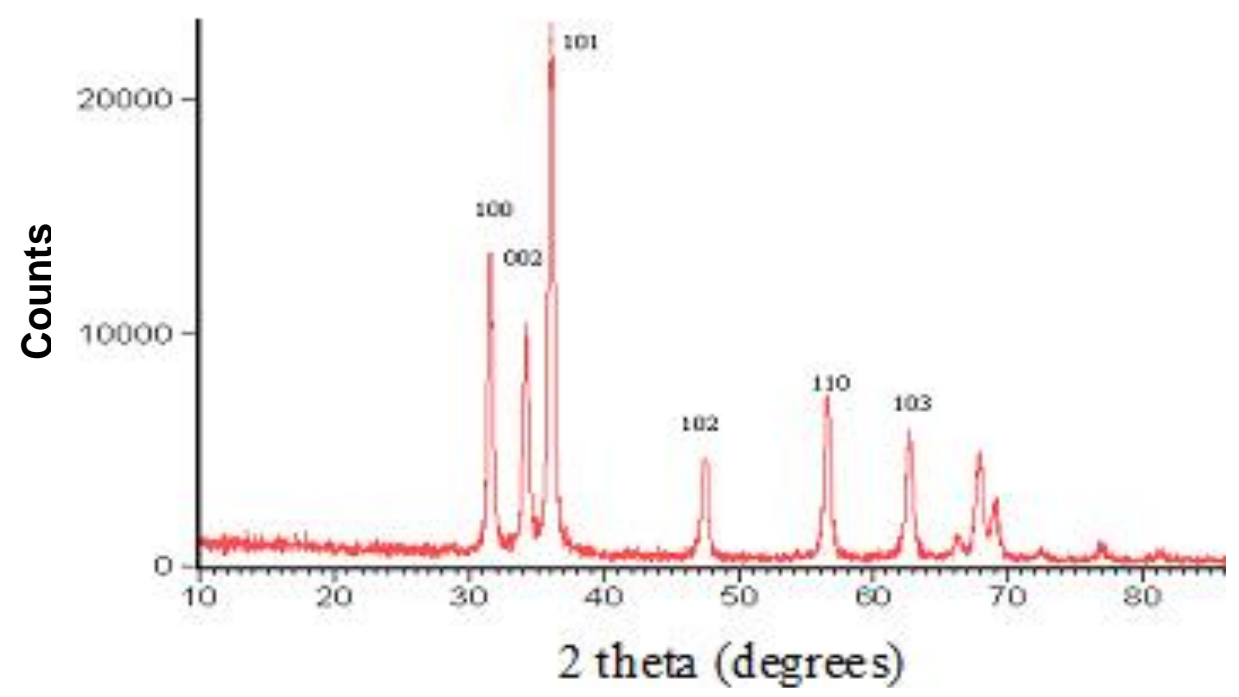

Figure 1. XRD spectrum of the black sediment.

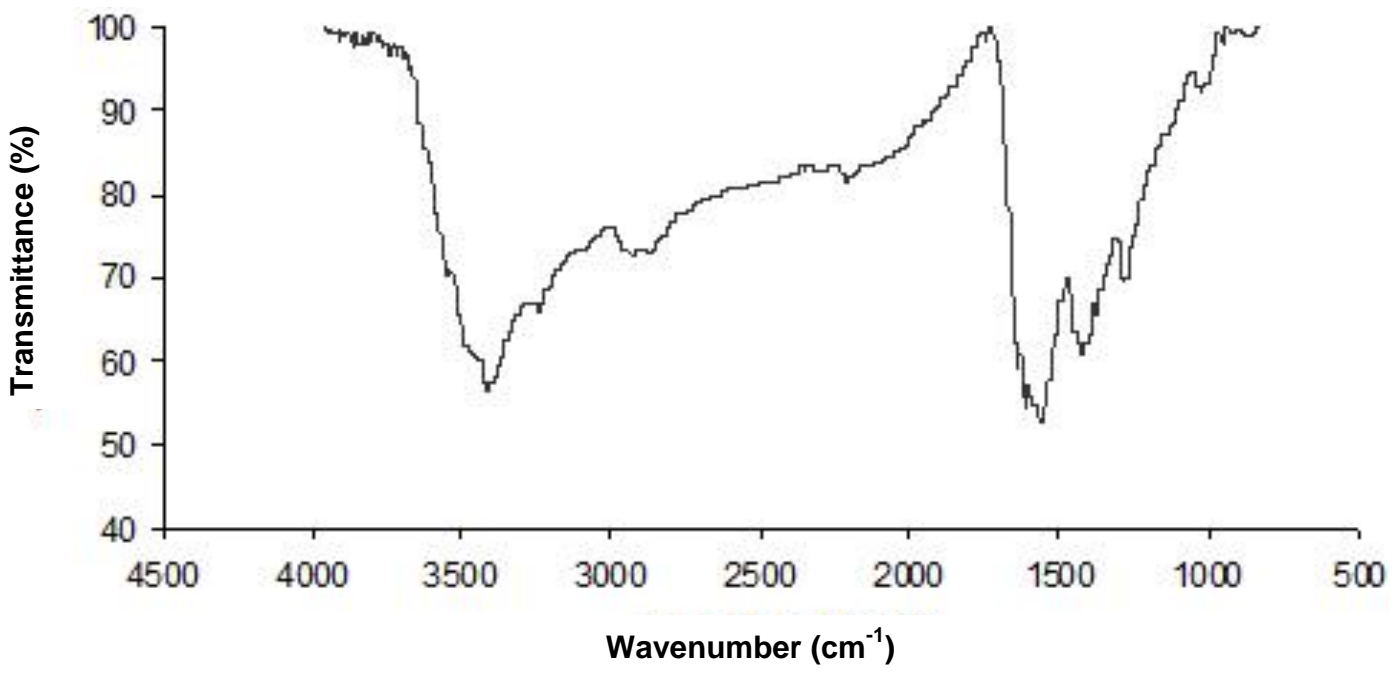

Figure 2. FTIR spectrum of the black sediment.

Labratories, England) and a white powder was obtained (called calcined nanoparticle powder (CNP)). X-ray diffractometer (XRD, PhilipsPW-3710) with $\mathrm{Cu}-\mathrm{Ka}$ radiation was used to determine the crystallographic structures. The surface and cross-section morphologies were characterized by a scanning electron microscope (SEM, Stero Scan 360). To identify the doped elements, Energy-dispersive X-ray spectroscopy (EDX, Stero Scan 360) was employed by a scanning electron microscope.

To evaluate the sensing properties of the resultant powder, $0.5 \mathrm{~g}$ of CNP was poured into a cylindrical mold with $13 \mathrm{~mm}$ diameter and was pressed under a pressure of 40 bar using a hand-press. The thickness of resultant tablets was $1.4 \mathrm{~mm}$. Sensitivity of the resultant tablets was measured with respect to ethanol at 300 to $400^{\circ} \mathrm{C}$. For the doping of iron (Fe) and copper $(\mathrm{Cu})$ sulfates with concentration of $2 \%$ atomic were dissolved in methanol. The details of construction and schematic illustration of the fabricated gas sensor have been reported in other work (Vaezi, 2008).

\section{RESULTS AND DISCUSSION}

\section{Characterization}

XRD pattern of the black sediment is as shown in Figure 1. According to JCPDS card No.36-1451, the XRD pattern shown in Figure 1 belongs to zinc-oxide with hexagonal structure.

However, studying Fourier transform infrared spectroscopy (FTIR, Bruker vector 33) of the black sediment (Figure 2), some amorphous organic structures are anticipated to be present in the structure. The infrared spectrum in Figure 2 shows absorption peaks.

The wave numbers are within the range of 400 to 4000 

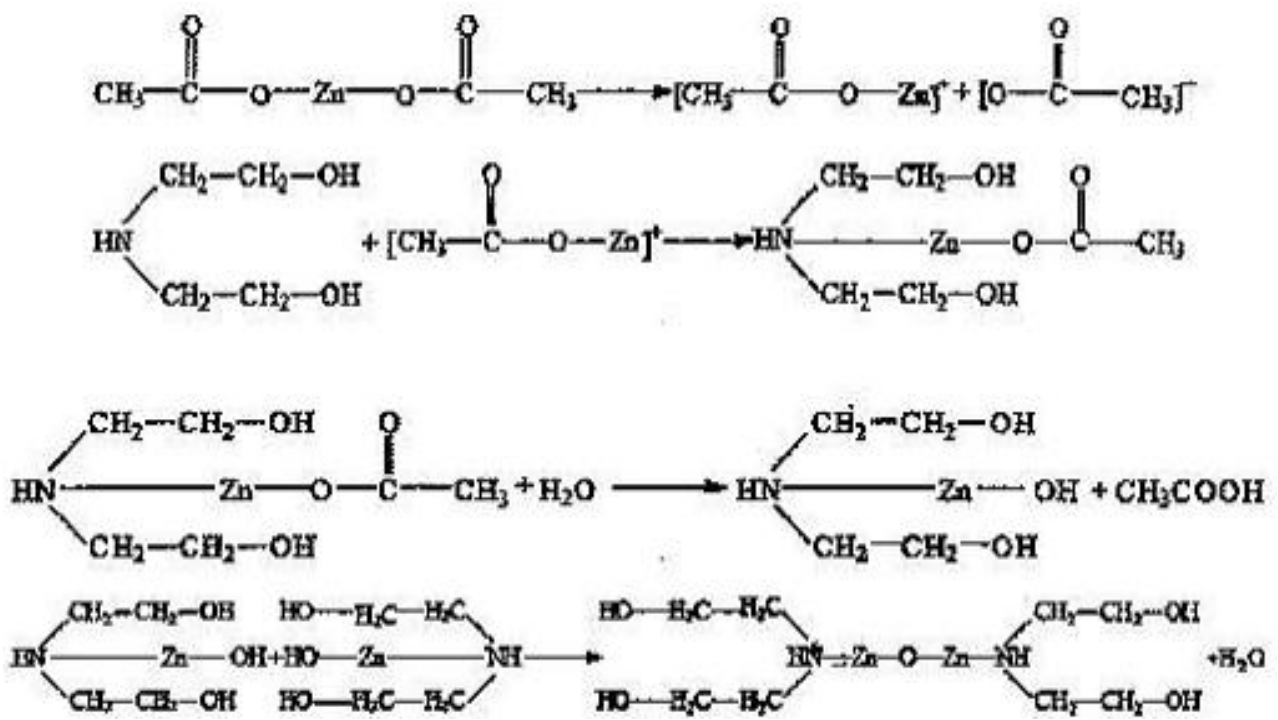

Figure 3. The reactions that occured in the forming of black sediment.

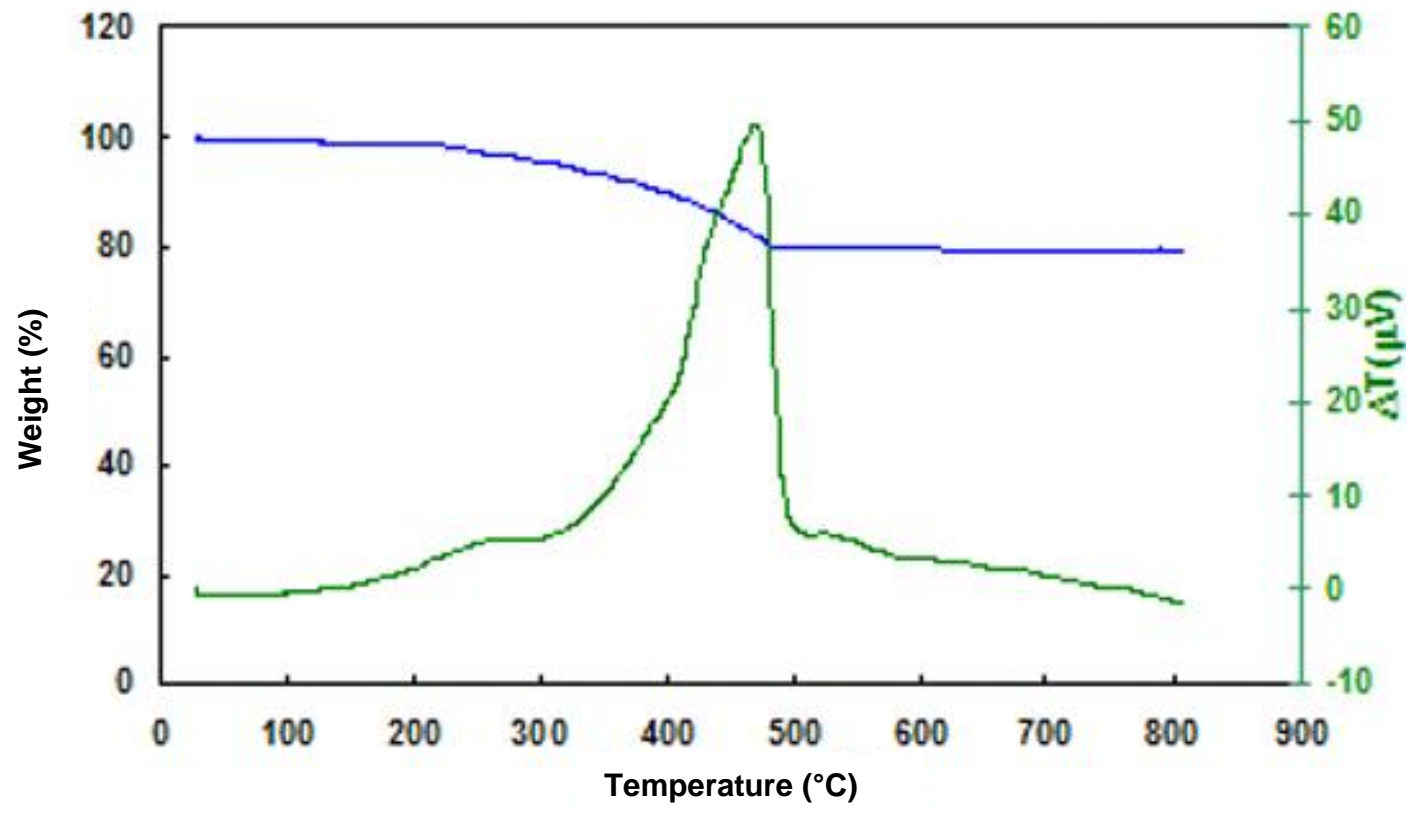

Figure 4. TGA-DTA diagram of the black sediment.

$\mathrm{cm}^{-1}$. The strong absorption happened at $3438 \mathrm{~cm}^{-1}$ and it corresponds to $\mathrm{O}-\mathrm{H}$ bond in the system. The strong broad absorption near $1557 \mathrm{~cm}^{-1}$ corresponds to $\mathrm{N}$ $\mathrm{H}$ bond. Other absorption peaks at 1422, 1281, 1021 and $546 \mathrm{~cm}^{-1}$ are associated with the bending bonds of $-\mathrm{CH}_{2}$, $\mathrm{C}-\mathrm{N}, \mathrm{C}-\mathrm{O}$ and $\mathrm{Zn}-\mathrm{O}$, respectively. Figure 3 illustrates the suggestions for the probable reactions.

Figure 4 shows TGA-DTA curves of the black sediment. Since our working temperature was $200^{\circ} \mathrm{C}$, weight loss is not significantly below $200^{\circ} \mathrm{C}$. At this temperature, thermal decomposition begins gradually, leading to a sharp peak in DTA graph. The peak is mainly due to organic compounds elimination and zinc alkoxide decomposition. A weight loss of about 20 wt $\%$ occurred below $475^{\circ} \mathrm{C}$. At this point, organic compounds vanish and hereafter the molecule is stable and the weight of the molecule is nearly constant without further weight loss, as suggested by DTA graph. Therefore, GNP was calcined at $500^{\circ} \mathrm{C}$.

The XRD spectra of pure $\mathrm{ZnO}$ and doped specimens 


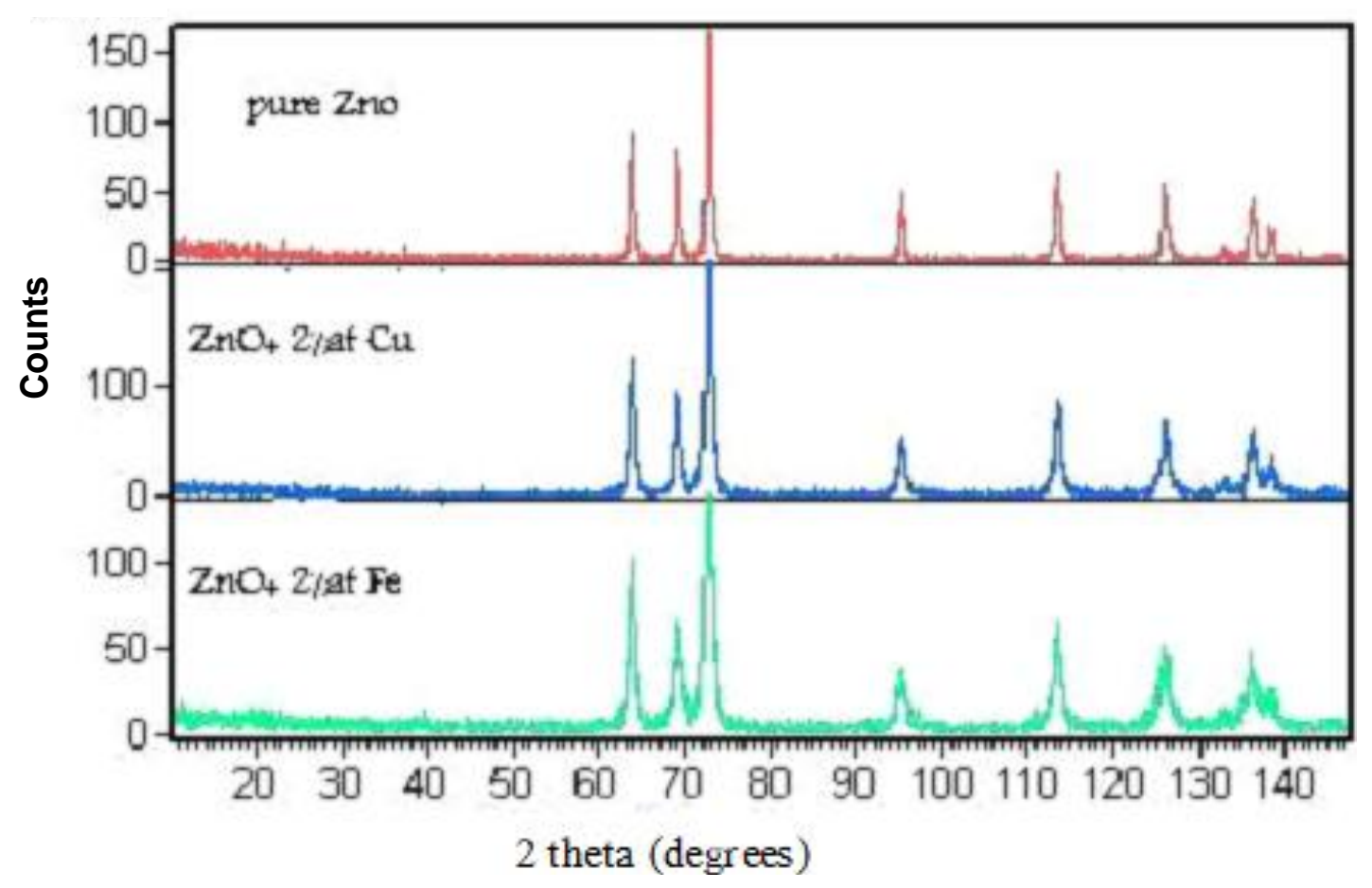

Figure 5. XRD spectra of pure $\mathrm{ZnO}$ and doped specimens.

are as shown Figure 5. All the peaks associated with zinc oxide are present as shown in Figure 5. Moreover, Figure 5 shows that there is no significant difference between XRD spectra of doped and pure specimens. Therefore, EDX spectra were used to identify doped elements. The average crystallites sizes were 26.5 and $38 \mathrm{~nm}$ in doped and pure specimens, respectively.

EDX analyses of doped specimens confirm the presence of doped elements (Figure 6). According to these analyses, atomic percentages of copper and iron were 1.54 and 1.49 , respectively. Figure 7 shows SEM images of zinc oxide nano-powder without and with dopants. Average crystallite size of particles in pure specimen was about $85 \mathrm{~nm}$, while average size of particles in specimens containing $2 \%$ atomic $\mathrm{Cu}$ and $\mathrm{Fe}$ were 68 and $853 \mathrm{~nm}$, respectively. In the case of specimen with $2 \%$ atomic $\mathrm{Fe}$, nano-wires with approximate diameter of $100 \mathrm{~nm}$ are also visible.

\section{Sensing properties}

When dealing with gas sensors, the most important parameter to be calculated is the sensitivity:

$$
S=\frac{R_{a}}{R_{g}}
$$

where $S$ is the sensitivity, $R_{a}$ is the resistance of sensor in the air and $R_{g}$ is the resistance of sensor in desired gas. In this method, tablets of $\mathrm{ZnO}$ nanopowder with gas concentration of $1000 \mathrm{ppm}$ were examined by gas sensors at temperature of 300 to $400^{\circ} \mathrm{C}$. As illustrated in Figure $8 \mathrm{a}$, sensitivity increases with increase in temperature from 300 to $370^{\circ} \mathrm{C}$, where sensitivity reaches a maximum value of 25 at $370^{\circ} \mathrm{C}$. After that, the sensitivity suddenly decreases to 19 at $390^{\circ} \mathrm{C}$. Since sensitivity is related to both $R_{a}$ and $R_{g}$, the sudden decrease may be attributed to the following reasons.

First, is the widely accepted phenomenon of chemisorptions when an n-type semiconductor gas sensor is presented in air. Chemisorption of oxygen molecules could happen on the surface in the form of $\mathrm{O}^{2-}, \mathrm{O}_{2}{ }^{2-}$ and $\mathrm{O}_{2}{ }^{-}$ions by capturing electrons from the conductance band, since the electronegativity of oxygen molecules is bigger than semiconductor. As a result, an electron-depleted space-charge layer in the surface region of the particle will be produced (Figure 9). Takata et al. (1976) found out that the stable oxygen ions were $\mathrm{O}_{2}^{-}$below $100^{\circ} \mathrm{C}, \mathrm{O}^{-}$between 100 and $300^{\circ} \mathrm{C}$, and $\mathrm{O}^{2-}$ above $300^{\circ} \mathrm{C}$. Therefore, oxygen adsorption plays an important role in the resistance of pellets and the amounts of such chemisorbed oxygen species depend strongly on the temperature.

Before $370^{\circ} \mathrm{C}$, air resistance increases with increase in the temperature. Since the oxygen species capture conduction electrons from the materials, this leads to a decrease in the electron concentration (Yang et al., 2009) and the depletion layer becomes bigger, because of the 

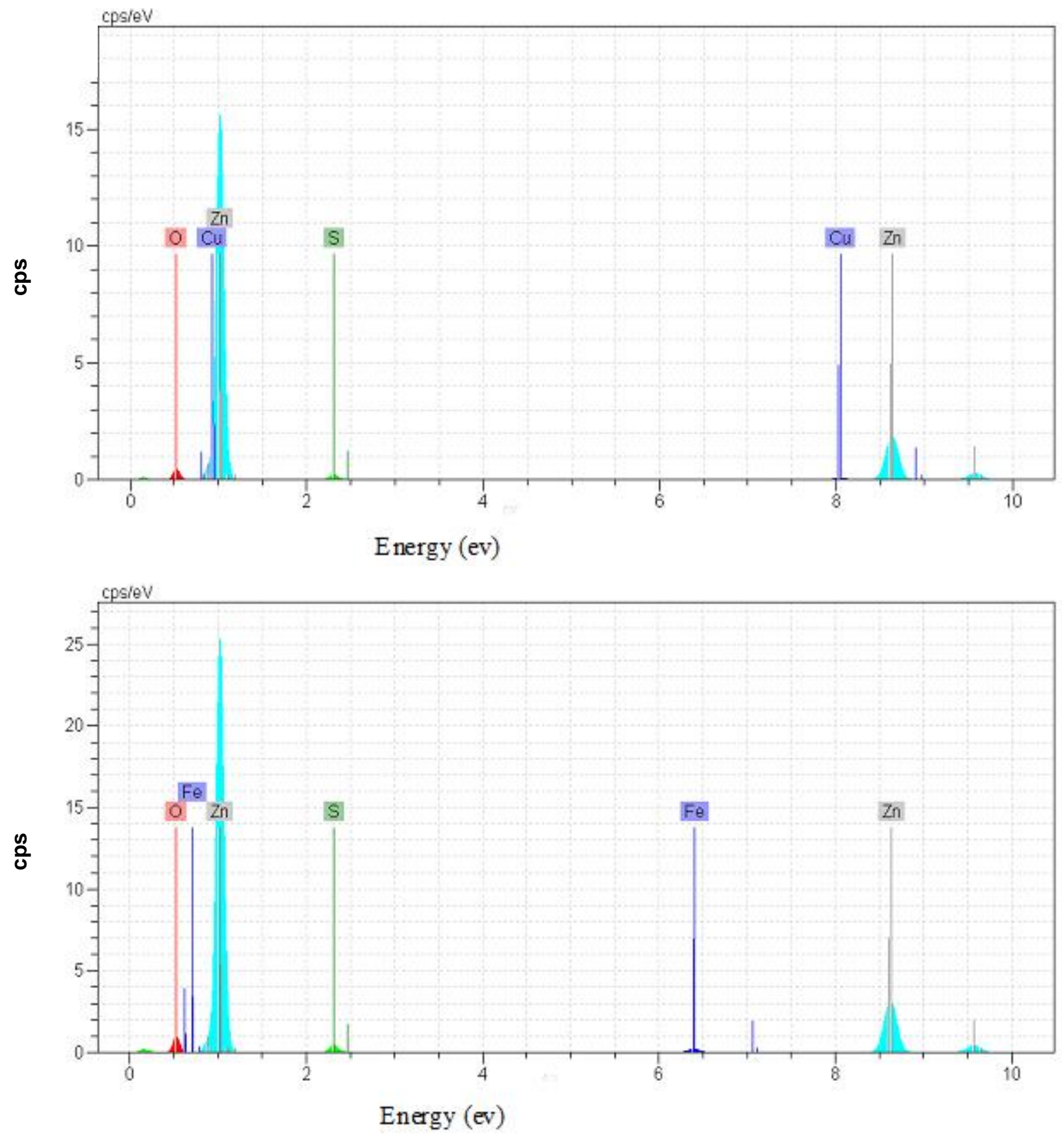

Figure 6. EDX spectra of nanopowder doped with (a) copper and (b) iron.

higher concentration of the adsorbed oxygen. But above $370^{\circ} \mathrm{C}$, the decrease in $R_{a}$ occurs since the adsorption reaction is exothermic and the reaction $\left(\mathrm{O}_{2}+2 \mathrm{e} \rightarrow 2 \mathrm{O}^{-}\right.$, $\mathrm{O}^{-}+\mathrm{e} \rightarrow \mathrm{O}^{2-}$ ) will proceed to the left. This causes reduction of the trapped electrons from the conductance band (Trivikrama and Tarakarama, 1999) and the enlargement of the depletion layer.

The next reason could be attributed to $R_{g}$. In the presence of the test gas $(R)$, chemisorption of gas molecules to the surface will result in RO molecules. As the temperature increases to $370^{\circ} \mathrm{C}$, there is greater adsorption of $\mathrm{RO}$ molecules (since the $\mathrm{RO}$ molecules leave the surface and the active sites remain free for the other gas molecules). As a result, charging of electrons in the conduction band occurs, the depletion layer becomes smaller, and the $R_{g}$ drops which is followed by an increase in the sensitivity. The reactions are expressed as follows (Sberveglieri et al., 2008; Yang et al., 2009):

$\mathrm{R}$ (gas) $\longleftrightarrow \mathrm{R}_{(\text {ads })}$

$\mathrm{O}_{2 \text { (gas) }}+2 \mathrm{e}^{-} \longleftrightarrow 2 \mathrm{O}^{-}{ }_{\text {(ads) }}$ 


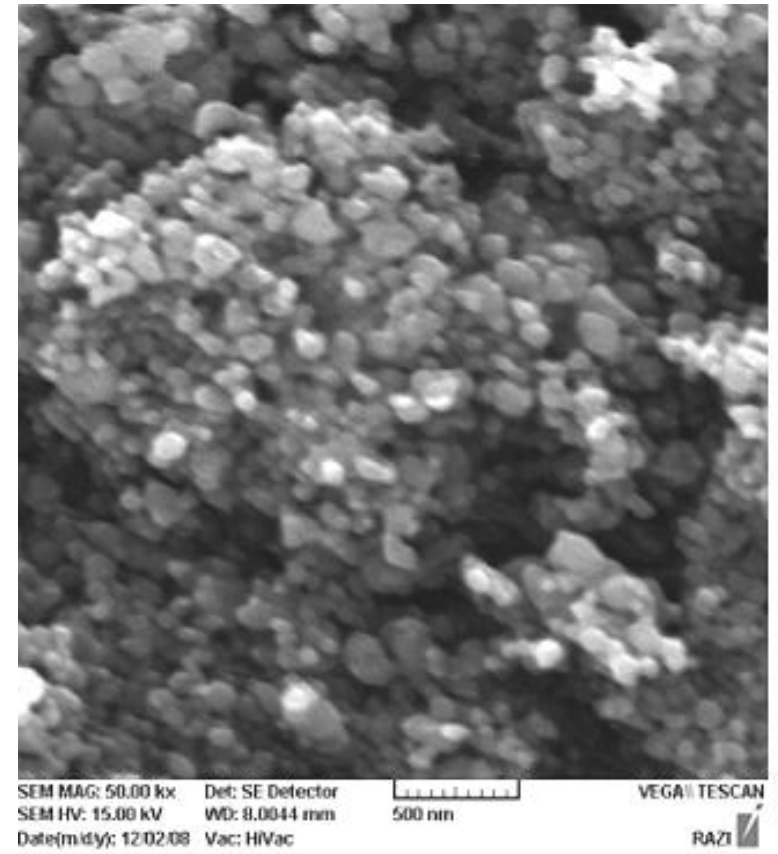

(a)

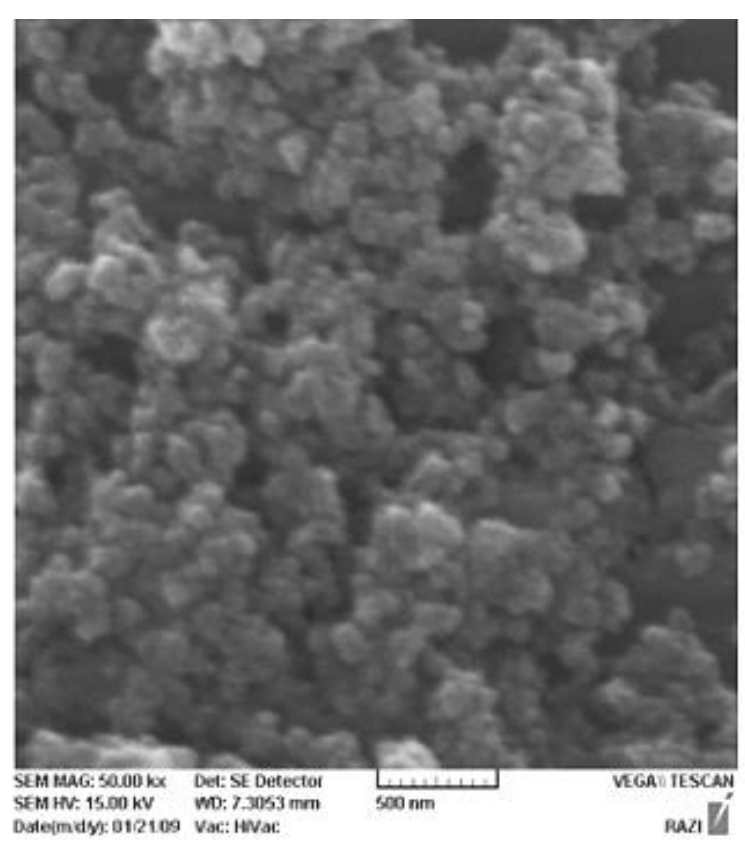

(b)

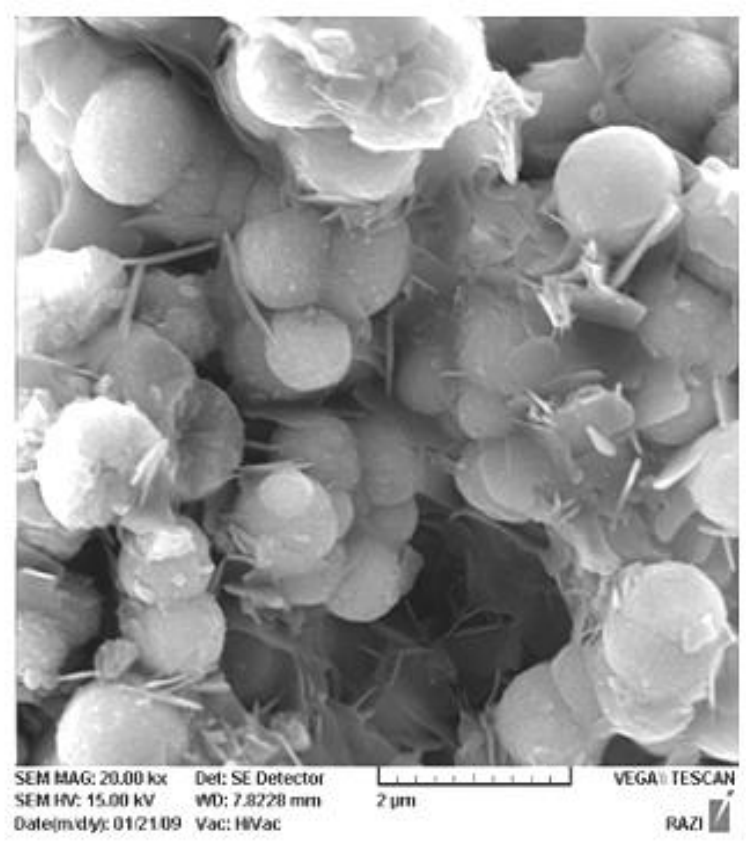

Figure 7. SEM images of zinc oxide nanopowder (a) without dopant, and doped with $2 \%$ at (b) copper and (c) iron.

$$
\mathrm{O}_{2}^{2-}{ }^{2} \text { (ads) }+2 \mathrm{e}^{-} \longleftrightarrow 2 \mathrm{O}^{2-}{ }^{\text {(ads })}
$$

$$
\mathrm{R}_{(\mathrm{ads})}+\mathrm{O}^{2-}{ }_{(\mathrm{ads})} \longleftrightarrow \mathrm{RO}+2 \mathrm{e}^{-}
$$

Here the testing gas is ethanol and therefore:
$\mathrm{C}_{2} \mathrm{H}_{5} \mathrm{OH}_{(\text {ads })}+6 \mathrm{O}^{2-}$ (ads) $\rightarrow 2 \mathrm{CO}_{2 \text { (gas) }}+3 \mathrm{H}_{2} \mathrm{O}_{(\text {gas })}+12 \mathrm{e}^{-}$

where the subscripts gas and ads mean gas and adsorbed, respectively.

After that, the physisorption rate of $R$ molecules will decrease. Therefore, fewer electrons will be charged in 

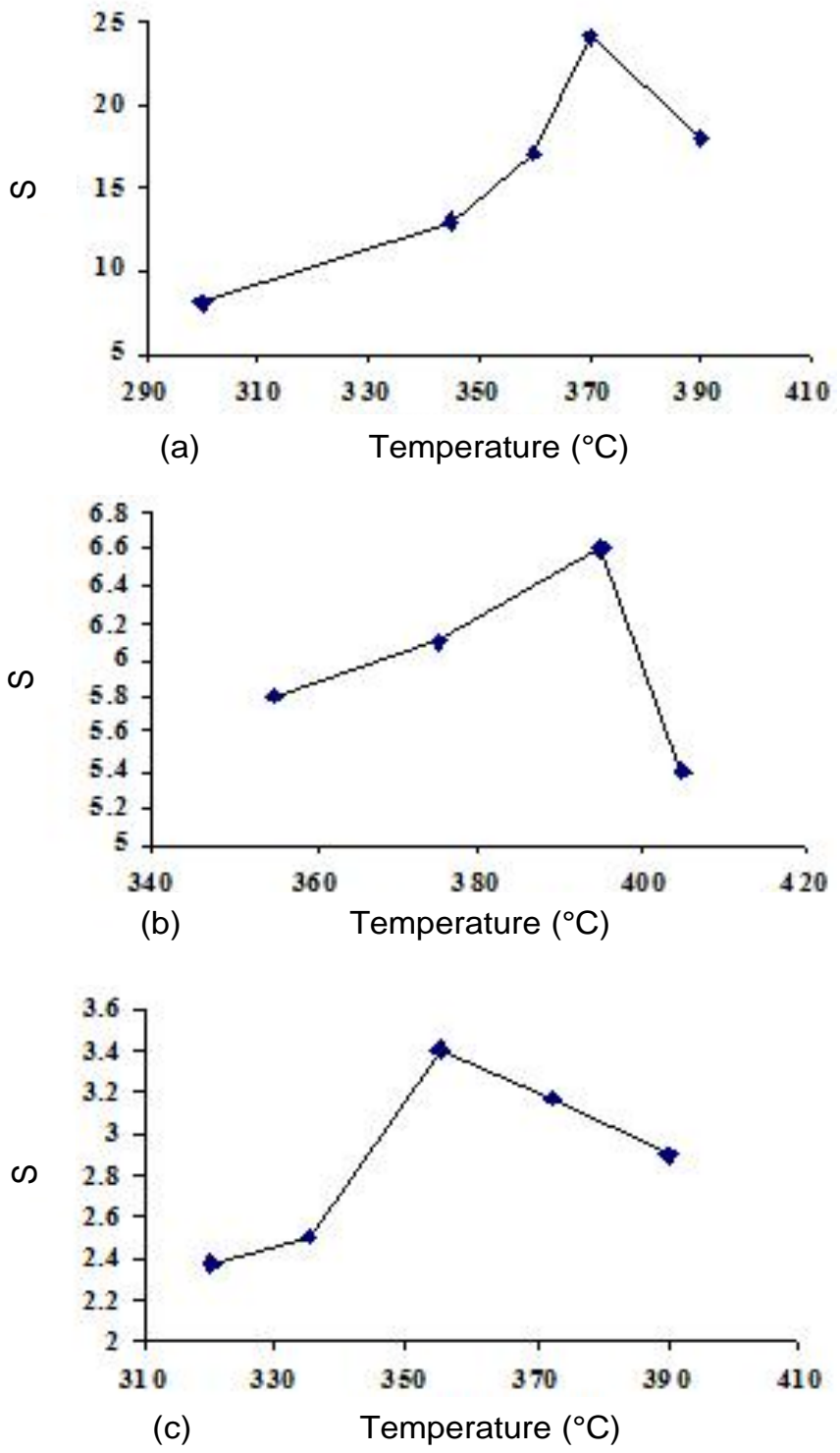

Figure 8. Sensitivity of zinc oxide nanopowder (a) without dopant, and (b) doped with $2 \%$ at (b) copper and (c) iron with respect to $1000 \mathrm{ppm}$ ethanol at different temperatures.

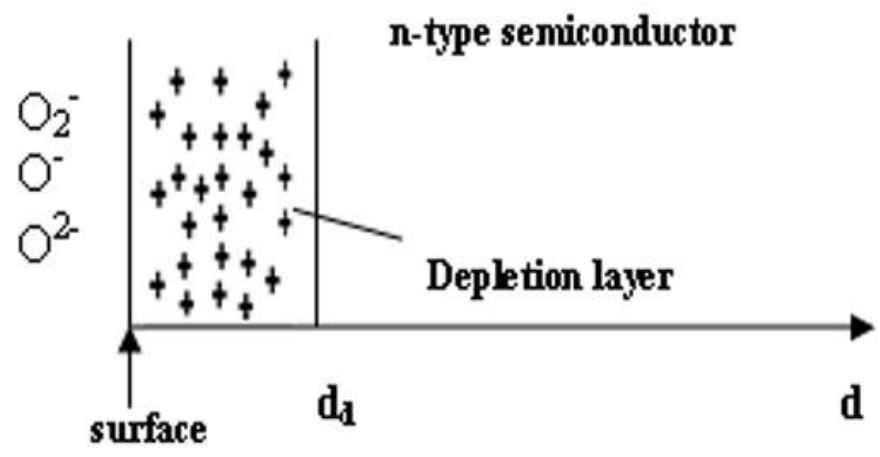

Figure 9. Electron-depleted layer model (d is distance from the surface and $d_{d}$ is the depth of depletion layer). the conduction band and the bigger depletion layer causes an increase in $R_{g}$. The absorbed ethanol gas on the surface decomposits to reaction as shown in Equations 7 and 8:

$\mathrm{C}_{2} \mathrm{H}_{5} \mathrm{OH} \rightarrow \mathrm{C}_{2} \mathrm{H}_{4}+\mathrm{H}_{2} \mathrm{O}$

$2 \mathrm{C}_{2} \mathrm{H}_{5} \mathrm{OH} \rightarrow 2 \mathrm{CH}_{3} \mathrm{CHO}+\mathrm{H}_{2}$

When $\mathrm{O}^{-2}$ reacts with ethanol gas absorbed on the surface of zinc oxide, reactions of Equation 9 and 10 occur as the following:

$\mathrm{C}_{2} \mathrm{H}_{4}+3 \mathrm{O}^{-2}(\mathrm{ad}) \rightarrow 2 \mathrm{CO}_{2}+2 \mathrm{H}_{2} \mathrm{O}+6 \mathrm{e}^{-}$

$2 \mathrm{CH}_{3} \mathrm{CHO}(\mathrm{ad})+10 \mathrm{O}^{-2}(\mathrm{ad}) \rightarrow 4 \mathrm{CO}_{2}+4 \mathrm{H}_{2} \mathrm{O}+20 \mathrm{e}^{-}$

The more temperature increases, the more the reaction of Equation 8 advances and the more free electrons is releases (according to the reaction of Equation 10). Therefore, increasing the temperature results to increase in the sensitivity (of course before temperature $370^{\circ} \mathrm{C}$ ) (Xu et al., 2008; Patil et al., 2007; Liewhiran and Phanichphant, 2007).

In the specimens doped with iron and copper, as illustrated in Figure $8 \mathrm{~b}$ and $\mathrm{c}$, the sensitivity of doped specimens decreased when compared with that of pure sample. As depicted in these Figures, sensitivity increased by temperature, however, there was a maximum point and the sensitivity decreased thereafter. The decrement can be explained as the following. When zinc oxide structure is doped with an element (e.g. iron or copper), its crystal lattice is distorted. This increases free energy of the system. Hence, increasing the temperature compels the system to decrease its free energy by growing the particles. As the particles grow, they expel the impurities out to the surface. The impurities then react with the resident oxygen forming copper oxide and iron oxide on the surface of zinc oxide particles.

Iron oxide and copper oxide are not catalyses for reaction between ethanol and oxygen. Furthermore, these elements decrease specific surface area of $\mathrm{ZnO}$ particles and consequently, decrease the sensitivity of $\mathrm{ZnO}$. In the case of doping with $\mathrm{Fe}, \mathrm{ZnO}$ particles are approximately 10 times larger. This is responsible for decrement of sensitivity.

\section{Conclusion}

Zinc oxide nanopowders are vitally important materials in gas sensors. At $475^{\circ} \mathrm{C}$, all volatile materials of black sediment (created by sol-gel method) were vaporized and the $\mathrm{ZnO}$ was synthesized successfully.

The sensitivity of $\mathrm{ZnO}$ nanopowder tablets increased when the temperature is raised up to $370^{\circ} \mathrm{C}$ and decreased thereafter. Same happened for the specimens 
doped with $\mathrm{Fe}$ and $\mathrm{Cu}$ (although the temperature at which maximum sensitivity occurred was different). In general, doping $\mathrm{Fe}$ and $\mathrm{Cu}$ had negative effect on the sensitivity of $\mathrm{ZnO}$.

\section{REFERENCES}

Bahari Y, Sadrnezhaad SK, Hosseini D (2008). NiO Nanoparticles Synthesis by Chemical Precipitation and Effect of Applied Surfactant on Distribution of Particle Size. J. Nanomat. Article ID 470595, doi:10.1155/2008/470595. p. 4.

Boukos N, Chandrinou C, Giannakopoulos K, Pistolis G, Travlos A (2007). Growth of $\mathrm{ZnO}$ nanorods by a simple chemical method. J. Appl. Phys. A., 88: 35-39.

Caglar Y, llican S, Caglar M, Yakuphanoglu F (2007). Effects of In, Al and $\mathrm{Sn}$ dopants on the structural and optical properties of $\mathrm{ZnO}$ thin films. J. Spectrochem. Acta A., 67: 1113-1119.

Carotta MC, Cervi A, Natale V, Gherardi S, Giberti A, Guidi V, Puzzovio D, Vendemiati B, Martinelli G, Sacerdoti M, Calestani D, Zappettini A, Zha M, Zanotti L (2009). ZnO gas sensors: A comparison between nanoparticles and nanotetrapods-based thick films. J. Sensor. Actuat. B-Chem., 137: 164-169.

Gomez H, Olvera M (2006). Ga-doped ZnO thin films: Effect of deposition temperature, dopant concentration, and vacuum-thermal treatment on the electrical, optical, structural and morphological properties. J. Mater. Sci. Eng. B., 134: 20-26.

Guangjian X, Guanghua C, Xuemei S, Xiaoming Y, Wang Y, Hong Y (2003). $\mathrm{ZnO}$ and $\mathrm{TiO}_{2}$ nanoparticles encapsulated in boron nitride nanocages. J. Micronelectr. Eng., 66: 70-76.

Jiaqiang X, Jianjun Hn, Yuan Z, Yu'an S, Bing X (2008). Studies on alcohol sensing mechanism of $\mathrm{ZnO}$ based gas sensors. J. Sensor Actuat. B-Chem., 132: 334-339.

Liewhiran C, Phanichphant S (2007). Improvement of Flame-made ZnO Nanoparticulate Thick Film Morphology for Ethanol Sensing. J. Sens., 7: 650-675.

Lima SAM, Cremona MR, Davolos M, Legnani C, Quirino WG (2007). Electroluminescence of zinc oxide thin-films prepared via polymeric precursor and via sol-gel methods. J. Thin Solid Films, 516: 165-169.

Min-Hung L, Chih-Hsiung H, Dong-Hwang C (2006). Preparation and properties of amorphous titania-coated zinc oxide nanoparticles. J. Solid State Chem., 179: 2020-2026.
Mosely PT (1997). Solid State Gas Sensor. Meas. Sci. Technol., pp. 65-83.

Niu X, Du W (2004). Preparation and gas sensing properties of ZnM2O4. J. Sensor. Actuat. B, 99: 405-409.

Paraguay FD, Yoshida MM, Morales J, Solis J, Estrada WL (2000). Influence of $\mathrm{Al}, \mathrm{In}, \mathrm{Cu}, \mathrm{Fe}$ and $\mathrm{Sn}$ dopants on the response of thin films $\mathrm{ZnO}$ gas sensor to ethanol vapour. J. Thin Solid Films, 373: 137-140.

Patil DR, Patil LA, Amalnerkar DP (2007). Ethanol gas sensing properties of Al2O3-doped $\mathrm{ZnO}$ thick film resistors. Bull. J. Mater. Sci., 30: 553-559.

Sberveglieri G, Nelli P, Groppelli S (2008). Oxygen gas sensing characteristics at ambient pressure of undoped and lithium-doped ZnO-sputtered thin films. J. Mater. Sci. Eng., 7: 63-68.

Sonawane Y, Kanade KG, Kale BB, Aiyer RC (2008). Electrical and gas sensing properties of self-aligned copper-doped zinc oxide nanoparticles. J. Mater. Res. Bull., 43: 2719-2726.

Takata M, Tsubone D, Yanagida H (1976). Dependence of Electrical Conductivity of $\mathrm{ZnO}$ on Degree of Sintering. J. Am. Ceram. Soc., 59: 4-8.

Trivikrama GS, Tarakarama D (1999). Gas sensitivity of ZnO based thick film sensor to NH3 at room temperature. J. Sensor Actuat. B., 55: 166-169.

Vaezi MR (2008). $\mathrm{SnO}_{2} / \mathrm{ZnO}$ double-layer thin films: A novel economical preparation and investigation of sensitivity and stability of doublelayer gas sensors. J. Mater. Chem. Phys., 110: 89-94.

Xu J, Han J, Zhang Y, Sun Y, Xie B (2008). Studies on alcohol sensing mechanism of $\mathrm{ZnO}$ based gas sensor. J. Sensor Actuat., 132: 334339.

Yadav BC, Srivastava R, Dwivedi CD, Pramanik P (2009). Synthesis of nano-sized $\mathrm{ZnO}$ using drop wise method and its performance as moisture sensor. J. Sensor Actuat. A.,153: 137-141.

Yang Z, Huang Y, Chen G, Guo Z, Cheng S, Huang S (2009). Ethanol gas sensor based on Al-doped $\mathrm{ZnO}$ nanomaterial with many gas diffusing channels. J. Sensor Actuat. B., 140: 549-556.

Yintang J (2008). Deposition of K-doped p type $\mathrm{ZnO}$ thin films on (0001) $\mathrm{Al}_{2} \mathrm{O}_{3}$ substrates. J. Mater. Lett., 62: 1899-1901.

Zeng DW, Xie CS, Zhu BL Zhu, Song WL, Wang AH (2003). Synthesis and characteristics of Sb-doped ZnO nanoparticles. Mater. Sci. Eng., 104: 68-72.

Zi-qiang X, Hong D, Yan L, Hang C (2006). Al-doping effects on structure, electrical and optical properties of c-axis-orientated ZnO:Al thin films. J. Mater. Sci. Semicon., 9: 132-135. 